\title{
Preparation of thermally stable phenylpolysiloxane fused silica capillary columns : optimization and evaluation of the deactivation by capillary GC and solid state 29Si NMR
}

\author{
Citation for published version (APA): \\ Wu, Q., Hetem, M. J. J., Cramers, C. A. M. G., \& Rijks, J. A. (1990). Preparation of thermally stable \\ phenylpolysiloxane fused silica capillary columns : optimization and evaluation of the deactivation by capillary \\ GC and solid state 29Si NMR. Journal of High Resolution Chromatography, 13(12), 811-816. \\ https://doi.org/10.1002/jhrc.1240131204
}

DOI:

10.1002/jhrc.1240131204

Document status and date:

Published: 01/01/1990

\section{Document Version:}

Publisher's PDF, also known as Version of Record (includes final page, issue and volume numbers)

\section{Please check the document version of this publication:}

- A submitted manuscript is the version of the article upon submission and before peer-review. There can be important differences between the submitted version and the official published version of record. People interested in the research are advised to contact the author for the final version of the publication, or visit the DOI to the publisher's website.

- The final author version and the galley proof are versions of the publication after peer review.

- The final published version features the final layout of the paper including the volume, issue and page numbers.

Link to publication

\footnotetext{
General rights

- You may freely distribute the URL identifying the publication in the public portal. follow below link for the End User Agreement:

www.tue.nl/taverne

Take down policy

If you believe that this document breaches copyright please contact us at:

openaccess@tue.nl

providing details and we will investigate your claim.
}

Copyright and moral rights for the publications made accessible in the public portal are retained by the authors and/or other copyright owners and it is a condition of accessing publications that users recognise and abide by the legal requirements associated with these rights.

- Users may download and print one copy of any publication from the public portal for the purpose of private study or research.

- You may not further distribute the material or use it for any profit-making activity or commercial gain

If the publication is distributed under the terms of Article $25 \mathrm{fa}$ of the Dutch Copyright Act, indicated by the "Taverne" license above, please 


\title{
Preparation of Thermally Stable Phenylpolysiloxane Fused Silica Capillary Columns Optimization and Evaluation of the Deactivation by Capillary GC and
Solid State ${ }^{29}$ Si NMR
}

Q. Wu, M. Hetem, Carel A. Cramers, and Jacques A. Rijks ${ }^{\star}$

Eindhoven University of Technology, Laboratory of Instrumental Analysis, P.O. Box 513, 5600 MB Eindhoven, The Netherlands

\author{
Key Words: \\ High temperature capillary GC \\ Deactivation \\ Polydiphenylvinylmethylhydrosiloxane \\ Solid-state ${ }^{29}$ Si NMR \\ Medium polarity stationary phases
}

\section{Summary}

The deactivation of fused silica capillary columns with a laboratory-made poly-diphenylvinylmethylhydrosiloxane copolymer has been investigated. The deactivation obtained at different temperatures and reaction times is characterized with a dual column capillary GC system [1]. In parallel, the effect of the silylation temperatures and reaction times on the nature, the structure, and the chemical properties of the deactivation layer has also been studied by solid-state ${ }^{29} \mathrm{Si}$ NMR spectroscopy. A fumed silica, Cab-O-Sil M5, was used as a model substrate for these spectroscopic studies.

The deactivated fused silica capillaries show an excellent thermal stability (up to $400^{\circ} \mathrm{C}$ ), a high resistance to solvolysis, and a minimal interaction to various critical test components. $A$ good wettability of the fused silica capillary columns deactivated with this reagent was confirmed by successful subsequent coating with polysiloxanes with different phenyl contents.

\section{Introduction}

Both the reduction of the column diameter for capillary LC, SFC, and high speed capillary GC, and high temperature capillary GC have recently been the main topics of the development of column technology. Chemical and physical inertness, thermal stability, sample capacity, and resistance to solvents are the most critical factors for column performance in capillary GC, particularly for small bore columns $\left(d_{c}<50 \mu \mathrm{m}\right)$. In the framework of a long-term systematic study on column deactivation, coating, and crosslinking, we recently reported the results of a study on the deactivation of fused silica capillary columns with polyvinylmethylhydrosiloxane (PVMHS) and polydiphenylvinylmethylhydrosiloxane (PDPVMHS) [2]. An excellent deactivation was obtained at optimum temperatures around $300^{\circ} \mathrm{C}$ for PVMHS and $350^{\circ} \mathrm{C}$ for PDPVMHS.

Presented at the Eleventh International Symposium on Capillary Chromatography, Monterey, CA, May 14-17, 1990.
In this study, only PDPVMHS was used for the deactivation of fused silica capillary columns with inner diameter of $250 \mu \mathrm{m}$. According to Lee and $\mathrm{co}$-workers [3-6], this type of reagents serves two purposes in the process of deactivation. The first one is to get rid of the active sites of the column wall by chemical reaction between the silicon hydride and surface silanol groups at the column wall. The second one is to increase the critical surface tension of the deactivation layer in order to get a compatible wettability for phenyl-containing stationary phases without loss of the deactivation. This is because of the phenyl groups present in the deactivation layer.

In previous studies [7-11], the loss of phenyl groups from the silica surface at temperatures above $250^{\circ} \mathrm{C}$ was observed when 1,3-diphenyl-tetramethyldisilazane (DPTMDS) was used as the deactivation reagent $[11,12]$. The two phenyl groups are attached to different silicon atoms, both together with two methyl groups. Blum and Eglinton [13] pointed out that asymmetrical substitution leads to a dipole moment at the respective silicon atoms, which makes it easier for nucleophilic attacks by silanol groups or traces of water. An improved thermal stability of a polymer will be obtained with the symmetrical substitution. This was the third reason to select PDPVMHS as the deactivation reagent in this study.

A fumed vitreous silica is used as a model substrate for detailed studies on the nature and the chemical structure of the deactivation layer and confirmation of the intended chemical reactions at the column wall. This approach has proved to be a powerful tool for studying surfaces after different treatments [7, 14, 15]. Using ${ }^{29} \mathrm{Si}$ Magic Angle Spinning (MAS) NMR valuable information is revealed on the structure and the properties of organo-siliceous groups at a non-porous silica surface after silylation. Furthermore, in this way additional information can be obtained on the relative amounts of the siliceous groups and the nature of the deactivation layer bonded to the silica surface. The effect of the deactivation temperatures and reaction times was also studied in this way. The chromatographic properties of fused silica capillaries which were 
deactivated under corresponding experimental conditions are correlated with the spectroscopic results.

Subsequently, some of the deactivated capillaries were coated with polysiloxane stationary phases with various phenyl contents up to $50 \%$ molar ratio. This has the aim of demonstrating the applicability of PDPVMHS as a deactivation reagent for the preparation of high temperature medium polarity fused silica capillary columns

\section{Experimental}

\subsection{Materials}

1,3,5,7-Tetramethylcyclotetrasiloxane $\left(\mathrm{D}_{4} \mathrm{H}\right), \quad$ 1,3,5,7-tetravinylmethylcyclotetrasiloxane $\left(\mathrm{D}_{4} \mathrm{Vi}\right)$, diphenyldimethoxysilane and polymethylhydro-siloxane (PS122, 85CS, fluid) were all purchased from Petrarch Systems (Bristol, PA, USA). These reagents were used without further purification.

Fused silica capillary columns with internal diameters of $320 \mu \mathrm{m}$, $250 \mu \mathrm{m}$, and $50 \mu \mathrm{m}$ were obtained from Poiymicro Technology (Phoenix, AZ, USA).

All solvents used were analytical grade (Merck AG, Darmstadt, FRG). The Cab-O-Sil M5 with a specific area of $200 \mathrm{~m}^{2} / \mathrm{g}$ was a gift from Heybroek \& Co. Handelmij. NV (Amsterdam, NL).

\section{Table 1}

Survey of the silylation conditions of fused silica capillaries (5 $\mathrm{m} \times 250 \mu \mathrm{m}$ i.d.) and different phenyl(p): vinyl(v): hydrogen(h) ratios.

\begin{tabular}{llll}
\hline Column No. & $p: \mathrm{v}: \mathrm{h}$ & \multicolumn{2}{l}{ Silylation condition } \\
& & $\begin{array}{l}\text { Temperature } \\
{\left[{ }^{\circ} \mathrm{C}\right]}\end{array}$ & Time $[\mathrm{h}]$ \\
\hline 1 & $50: 7: 43$ & 320 & 2 \\
& $50: 7: 43$ & 350 & 2 \\
3 & $50: 7: 43$ & 350 & 10 \\
4 & $6: 1: 93$ & 350 & 2 \\
5 & $21: 3: 76$ & 350 & 2 \\
6 & $28: 4: 68$ & 350 & 2 \\
7 & $35: 5: 60$ & 350 & 2 \\
\hline
\end{tabular}

\subsection{Synthesis of the Deactivation Reagents}

PDPVMHS was synthesized from diphenyldimethoxysilane and $\mathrm{D}_{4} \mathrm{Vi}$ and $\mathrm{D}_{4} \mathrm{H}$ (molar ratio $=50: 7 ; 43$ ) according to the procedure reported in ref. [2]. In order to vary the portion of phenyl, a fixed volume of PDPVMHS copolymer was mixed with different volumes of polymethylhydrosiloxane (PMHS).

\subsection{Deactivation and Testing Procedure}

Prior to deactivation, the columns were treated with a $10 \% \mathrm{HC} 1$ solution at $150^{\circ} \mathrm{C}$ for $1 \mathrm{~h}$. Then the columns were rinsed successively with a $2 \% \mathrm{HCl}$ solution and water until neutral and finally dried at $250^{\circ} \mathrm{C}$ for $2 \mathrm{~h}$ while flushing with He. Thereafter, the columns were coated dynamically with a $5 \%$ solution of deactivation reagent in $n$-pentane solvent and flushed with $\mathrm{He}$ for 30 min. After flame sealing both ends, the silylation was carried out at different temperatures and reaction times (cf. Table 1). After completion of the deactivation the capillaries were carefully rinsed with $10 \mathrm{ml}$ dichloromethane and tested with a dual column system as described by Schomburg et al. [1]. The system consists of a short high quality home made PMHS deactivated OV-1 precolumn ( $10 \mathrm{~m} \times 250 \mu \mathrm{m}$ i.d., film thickness, $\left.d_{\mathrm{f}}=0.25 \mu \mathrm{m}\right)$ and the series coupled PDPVMHS deactivated capillaries.

A Packard Becker GC instrument (Model 430, Packard Becker, Delft, NL) was used for this purpose. A test mixture (cf. Table 2) which contains components with different functional groups and adsorptivities was used for the evaluation of the deactivated columns in a similar way as described in a previous paper [15]. Peak areas are normalized to $n$-decane and corrected for relative weight differences of the test substances but not corrected for their respective response factors. A Varian GC Model 3400 (Varian, CA, USA) was used for the evaluation of the coated columns and various applications.

\subsection{Silylation of Cab-O-Sil and ${ }^{29}$ Si Solid State NMR Measurements}

The Cab-O-Sil was pretreated by ignition and rehydration as described before [14] and stored over $\mathrm{P}_{2} \mathrm{O}_{5}$ in a vacuum desiccator for several weeks. This dried Cab-O-Sil was coated with a particular reagent. Approximately $1 \mathrm{~g}$ of $\mathrm{Cab}-\mathrm{O}-\mathrm{Sil}$ was added to a solution of $10 \%$ of PDPVMHS in n-pentane and mixed by sonification. After slowly evaporating the solvent at room temperature with a rotary evaporator, the deactivation layer was deposited on the silica surface with a film thickness of approximately $5 \mathrm{~nm}$. The coated $\mathrm{Cab}-\mathrm{O}$-Sil was then dried in an oven at

Table 2

Composition of the test mixture.

\begin{tabular}{lllll}
\hline $\begin{array}{l}\text { Precolumn } \\
\text { elution order }\end{array}$ & Components & Codes & $\begin{array}{l}\text { Concentration } \\
{[\mathrm{mg} / \mathrm{l}]}\end{array}$ & $\begin{array}{l}\text { Representative for } \\
1\end{array}$ \\
\hline 1 & decane & $\mathrm{C}_{10}$ & 119.0 & - \\
2 & 1-octanol & $\mathrm{C}_{8}-\mathrm{OH}$ & 112.4 & silanol, hydrogen bond \\
3 & 2,6 -dimethylphenol & $\mathrm{DMP}$ & 118.3 & basic sites \\
4 & undecane & $\mathrm{C}_{11}$ & 116.6 & - \\
5 & 2,6 -dimethylaniline & $\mathrm{DMA}$ & 114.7 & acid sites, silanol \\
6 & dodecane & $\mathrm{C}_{12}$ & 114.4 & - \\
7 & decylamine & $\mathrm{C}_{10}-\mathrm{NH}_{2}$ & 116.4 & acid sites, silanol, exposed siloxane bridge \\
8 & tridecane & $\mathrm{C}_{13}$ & 107.8 & - \\
9 & nicotine & $\mathrm{Nic}$ & 121.0 & acid sites, silanol \\
10 & tetradecane & $\mathrm{C}_{14}$ & 128.4 & - \\
\hline
\end{tabular}


$100^{\circ} \mathrm{C}$ under reduced pressure for $1 \mathrm{~h}$. A quartz ampoule filled with about $0.3 \mathrm{~g}$ of coated $\mathrm{Cab}-\mathrm{O}$-Sil was repeatedly evacuated and filled with He up to atmospheric pressure. After sealing the tube to a volume of about $8 \mathrm{ml}$, the ampoule was wrapped in aluminium foil and heated to the required silylation temperature for $16 \mathrm{~h}$. The ampoule was opened after silylation and the content was rinsed twice with dichloromethane and subsequently dried overnight at $110^{\circ} \mathrm{C}$ under reduced pressure. Solid state ${ }^{29} \mathrm{Si} \mathrm{NMR}$ spectra of the samples listed in Table 3 were obtained with a Bruker CXP300 spectrometer at $59.63 \mathrm{MHz}$, in a way similar to that discussed extensively in a previous paper [15]

\section{Table 3}

\section{Survey of the PDPVMHS silylated Cab-O-Sil samples.}

\begin{tabular}{lll}
\hline Sample No. & \multicolumn{2}{l}{ Silytation conditions } \\
& Temperature $\left[{ }^{\circ} \mathrm{C}\right]$ & Time $[\mathrm{h}]$ \\
\hline 1 & 280 & 16 \\
2 & 300 & 16 \\
3 & 320 & 16 \\
4 & 360 & 16 \\
\hline
\end{tabular}

The carbon contents of the silylated Cab-O-Sil samples were determined with a Perkin Elmer 240 Element Analyzer (Perkin Elmer, Norwalk, CT, USA).

\section{Results and Discussion}

\subsection{Evaluation of the Deactivated Capillaries}

The performance of the deactivated capillaries at different reaction temperatures and reaction times is evaluated chromatographically. The chromatographic evaluation consists in a careful observation of the chromatograms of the test mixture obtained with the dual column system. Peak shape, peak retention (expressed as Kováts retention indices), and normalized peak areas of the critical test components are used for this purpose. Representative chromatograms $\left(100^{\circ} \mathrm{C}\right.$, isothermal) of the precolumn and the precolumn connected to one of the deactivated columns (No. 5) are shown in Figure 1. These chromatograms show no significant differences in peak shape. Only the height ratio of
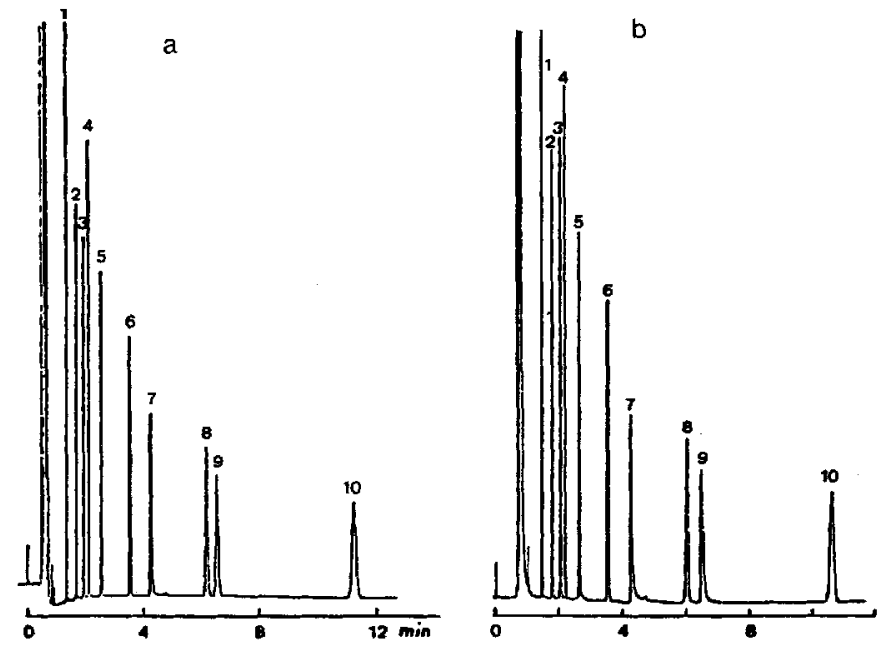

Figure 1

Representative chromatograms of the test mixture on a) precolumn and b) precolumn plus deactivated column no. 5. For test conditions see text and peak identification, see Table 2.

peaks 2 and 3 is slightly changed. This might be caused by slight shifts in the peak positions. Corresponding normalized peak areas and Kováts retention indices of the test components for a number of capillaries deactivated with PDPVMHS (cf. Table 1) are given in Table 4.

Referring to our results in a previous paper [2] and taking into account the normalized peak areas given in Table 4 for the columns \#1-3 (cf. Table 1) it can be concluded that an optimum deactivation is achieved at a silylation temperature of $350^{\circ} \mathrm{C}$ and a reaction time of $2 \mathrm{~h}$. Extension of the reaction time did not show any further improvement (cf. column \#2 and \#3).

The difference in retention indices from the precolumn and the series of precolumn coupled with the deactivated columns can be considered as an indication of the retention behavior from the deactivation layer on the deactivated column. The obtained retention behavior is mixed by the non-polar coated precolumn $\left(d_{f}=0.25 \mu \mathrm{m}\right)$ and the deactivated capillary column with an estimated film thickness of a few monolayers [6]. A new interface

\section{Table 4}

Normalized peak areas (NA) and Kováts retention indices (RI) at $100^{\circ} \mathrm{C}$ of the test components of the deactivated columns.

\begin{tabular}{|c|c|c|c|c|c|c|c|c|c|c|}
\hline \multirow[t]{2}{*}{ Column No. } & \multicolumn{2}{|c|}{ 1-octanol } & \multicolumn{2}{|c|}{ 2,6-DMP } & \multicolumn{2}{|c|}{$\begin{array}{l}\text { Test components } \\
2,6 \text {-DMA }\end{array}$} & \multicolumn{2}{|c|}{ Decylamine } & \multicolumn{2}{|c|}{ Nicotine } \\
\hline & NA & $\mathrm{RI}$ & NA & RI & $\mathrm{NA}$ & $\mathrm{RI}$ & $\mathrm{NA}$ & RI & $\mathrm{NA}$ & RI \\
\hline Precolumn & 85 & 1051.5 & 96 & 1081.6 & 101 & 1136.8 & 86 & 1233.9 & 91 & 1309.1 \\
\hline 1 & 83 & 1057.0 & 95 & 1090.8 & 100 & 1150.7 & 70 & 1242.7 & 84 & 1322.5 \\
\hline 2 & 85 & 1058.1 & 95 & 1093.7 & 102 & 1152.2 & 81 & 1240.5 & 88 & 1323.7 \\
\hline 3 & 85 & 1057.9 & 95 & 1092.8 & 102 & 1152.0 & 80 & 1239.4 & 88 & 1322.7 \\
\hline 4 & 85 & 1052.7 & 97 & 1084.4 & 102 & 1140.7 & 75 & 1236.6 & 86 & 1313.5 \\
\hline 5 & 85 & 1055.2 & 95 & 1086.3 & 100 & 1143.2 & 86 & 1235.7 & 88 & 1316.6 \\
\hline 6 & 86 & 1257.7 & 97 & 1092.0 & 103 & 1148.9 & 82 & 1239.3 & 91 & 1321.8 \\
\hline 7 & 85 & 1256.1 & 93 & 1090.6 & 100 & 1150.2 & 80 & 1238.7 & 90 & 1322.4 \\
\hline
\end{tabular}


that allows the selective measurement of the polarity of such short and thin film capillaries is in the final stage of development.

Nevertheless, it can be observed that the retention behavior of the deactivated capillaries increases with increasing content of phenyl functional groups (columns \#4-7 and \#2). This shows that phenyl groups are incorporated in the deactivating layer which is a prerequisite for homogeneous coating of compatible polarity stationary phases.

In order to check the thermal stability of the deactivated capillaries, column No. 2 was reheated at $350^{\circ} \mathrm{C}$ for $40 \mathrm{~h}$. No changes in the column activity were noted after this treatment. The insolubility of the deactivation layer was tested by rinsing the column with $10 \mathrm{ml}$ each of $n$-pentane, acetone, and dichloromethane. Neither the normalized peak areas nor the retention indices were changed. Therefore, it may be concluded that a thin rigid and non-extractable slightly polar deactivation layer is obtained with a good thermal stability.

\subsection{Evaluation of the Deactivation of Cab-O-Sil Samples with Solit State ${ }^{29}$ Si NMR}

A representative high resolution liquid ${ }^{29} \mathrm{Si}$ NMR spectrum of the synthesized PDPVMHS deactivation agent is depicted in Figure 2.

The structure of the most relevant chemical shifts for the liquid reagent as well as the silylated $\mathrm{Cab}-\mathrm{O}-\mathrm{Sil}$ are presented in Figure 3. Obviously all the required functional groups are present in the PDPVMHS deactivation reagent.

Solid state ${ }^{29} \mathrm{Si}$ CP-MAS NMR spectra of the silylated Cab-O-Sil samples (Table 3: \#1-4) are given in Figure 4. The corresponding relative ratios of the ${ }^{29} \mathrm{Si}$ CP-MAS NMR signals of bonded siliceous moieties of these samples are presented in Table $\mathbf{5}$.

From the results given in Figure 4 and Table 5 the presence of the methyltrisiloxysilane group $\left(\mathrm{T}_{3}\right)$ in the solid state ${ }^{29} \mathrm{Si}$ NMR spectra, it can be concluded that intra and/or intermolecular crosslinking is present in the surface polymer layer of the Cab-O-Sil samples. Its amount is increasing with increasing temperature which most probably results in a more rigid and dense cross-linked layer at the Cab-O-Sil surface.

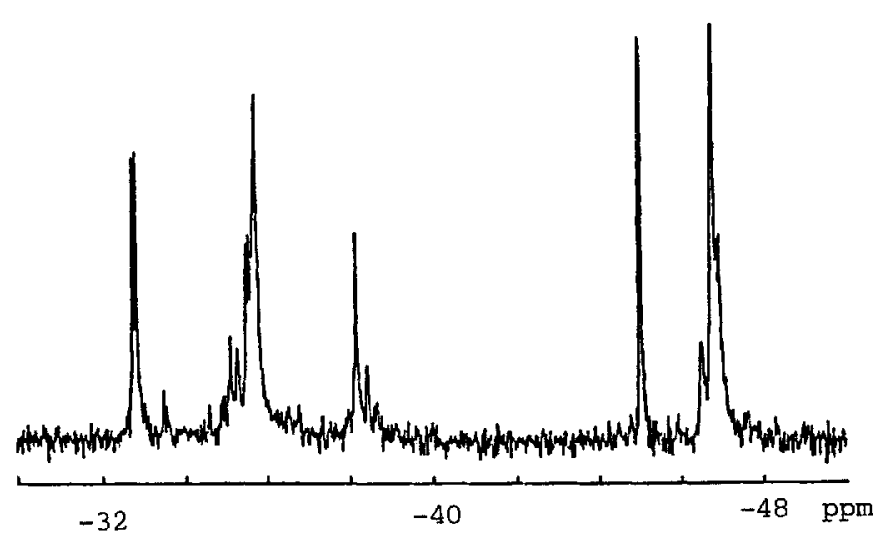

Figure 2

High resolution liquid ${ }^{29} \mathrm{Si}$ NMR spectrum of the synthesized PDPVMHS copolymer: molar ratio $=50: 7: 43, N_{s}=5300$, puise interval time $\mathbf{3 0} \mathrm{s}$, acquisition time $=\mathbf{1 0 0} \mathrm{ms}$.

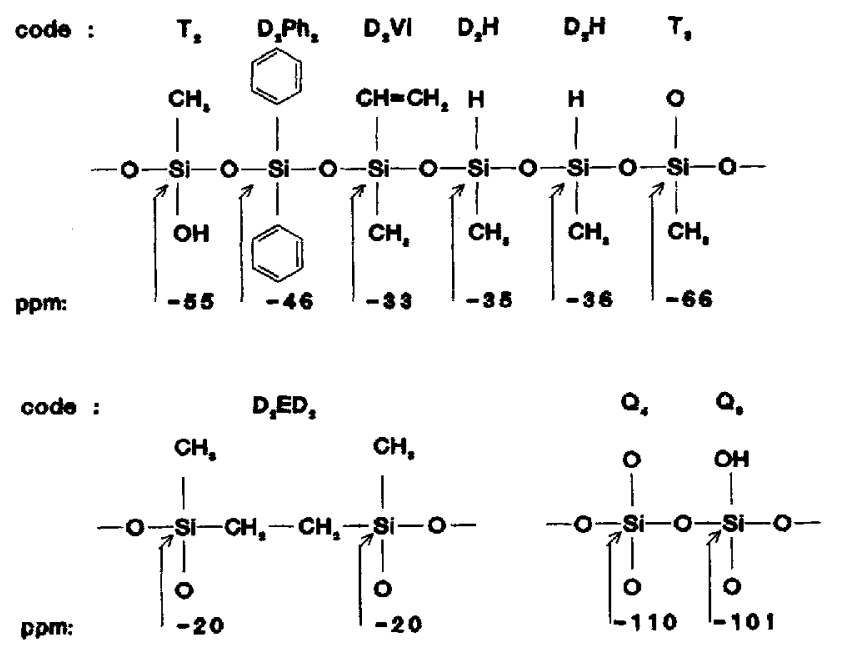

Figure 3

Structures and functionality notation codes of the most relevant siliceous surface moleties and their corresponding chemical shifts.

1

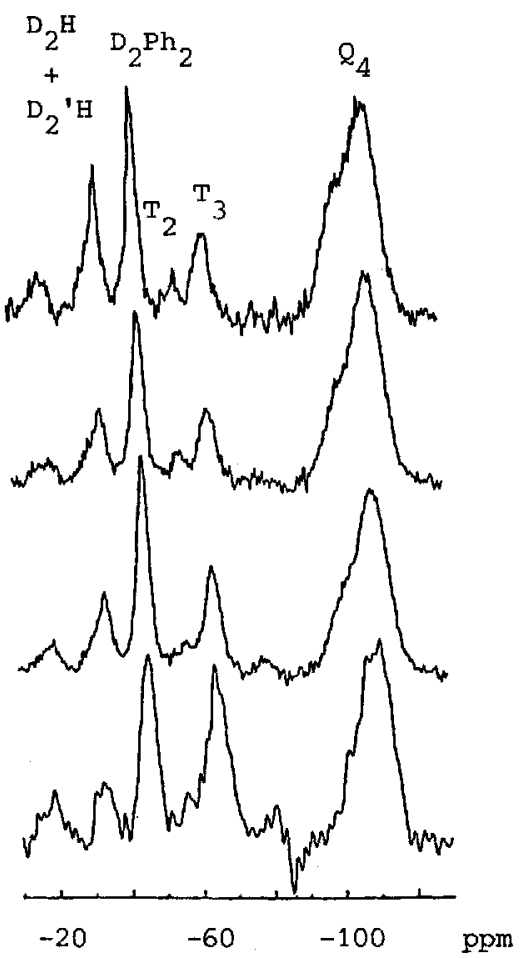

Figure 4

Solid state ${ }^{29}$ Si CP-MAS NMR spectra of PDPVMHS silylated CabO-Sil samples. (Table 3: \# 1-4).

While the surface silanol concentration at the Cab-O-Sil surface is rather large, surface attachment by means of a reaction between surface silanols and hydrosiloxane most likely also occurs to a large extent. Another, non-desirable cross-linked product, $\mathrm{D}_{2} \mathrm{ED}_{2}$ $(\approx 20 \mathrm{ppm})$ was produced by reaction of silicon hydride and vinyl 


\section{Table 5}

Relative ratios of the ${ }^{29} \mathrm{Si}$ NMR signals of bonded siliceous moieties of the silylated Cab-O-Sil samples.

\begin{tabular}{lcccrc}
\hline \multirow{2}{*}{ Sample no. } & \multicolumn{5}{l}{ Relative ratios of ${ }^{29} \mathrm{Si} \mathrm{NMR}$ signals } \\
& $\mathrm{D}_{2} \mathrm{ED}_{2}$ & $\mathrm{D}_{2} \mathrm{H}+\mathrm{D}_{2}^{\prime} \mathrm{H}$ & $\mathrm{D}_{2} \mathrm{Ph}_{2}$ & $\mathrm{~T}_{2}$ & $\mathrm{~T}_{3}$ \\
\hline 1 & 7 & 26 & 40 & 10 & 17 \\
2 & 6 & 17 & 39 & 9 & 18 \\
3 & 7 & 18 & 39 & - & 36 \\
4 & 11 & 14 & 39 & - & 36 \\
\hline
\end{tabular}

groups incorporated in the polymer. Referring to a recently published study on silylation reactions with a different reagent [15], it can be concluded from the ${ }^{29} \mathrm{Si}$ CP-MAS NMR spectra of the silylated Cab-O-Sil samples, that a relatively thin layer was formed $(1-2 \mathrm{~nm})$ instead of $5 \mathrm{~nm}$ calculated from the coating ratios.

Experimentally, an average carbon content of $17.6 \%$ was obtained by elemental analysis of the rinsed silylated $\mathrm{Cab}-\mathrm{O}$-Sil samples. Compared to the expected carbon content (about $30 \%$ ) in the coated $\mathrm{Cab}-\mathrm{O}$-Sil, a considerable amount of the deactivation reagent is washed away by solvent flushing of the deactivated $\mathrm{Cab}-\mathrm{O}$-Sil samples after silylation

Further cross-linking of the polymer, prevented by the large steric hindrance of diphenyl groups could be a possible explanation. The thermal degradation of the polymers should also be taken into account for this [16]. Although, a significant part of the reagent is lost by solvent rinsing, owing to inferior cross-linking, the final result is a rigid thin and stable network consisting of short polymer chains bounded to the silica surface. With the silylation conditions applied in this study, the ${ }^{29} \mathrm{Si}$ CP-MAS NMR resonances showing thermal decomposition of diphenyldisiloxysilane groups were not observed. Both phenyl groups remained chemically bonded to the siloxysilane copolymer at silylation temperatures up to $360^{\circ} \mathrm{C}$. Loss of phenyl groups would have been accompanied by transformation into other moieties, which have not been observed in the spectra. With 1,3-diphenyltetramethyldisilazane, which has been often used as a silylation reagent, phenyl losses were observed already at temperatures above $250^{\circ} \mathrm{C}[7,11]$. This leads to a decreased wettability of the capillaries.

\subsection{Evaluation of Some PDPVMHS Deactivated Capillaries after Coating and Crosslinking}

Although an extensive study on the influence of cross-linking is being performed, the performance of some of the deactivated capillaries after coating or coating and cross-linking is briefly discussed hereafter.

Some representative chromatograms obtained on the deactivated capillaries \# 4, 5, and 7 (cf. Table 1) after coating and subsequent crosslinking are presented in Figure 5. For detailed information about the preparation procedures see Table 6 . In agreement with the results reported in a previous paper [2], it follows from Figures $5 a$ and $b$, that the effect of the retention behaviour of the deactivation layer on the overall performance of the coated cross-linked columns cannot be neglected. The relative positions of 2,6-dimethylaniline (DMA) and n-dodecane and nicotine com-

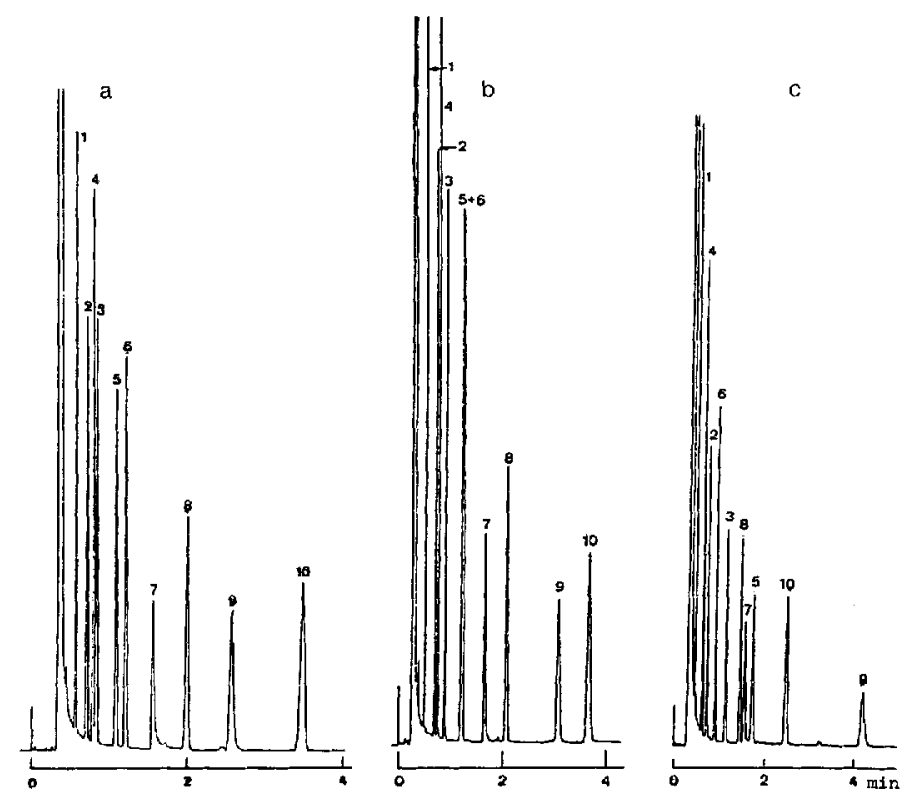

Figure 5

Representative chromatograms of coated cross-linked PDPVMHS deactivated capillaries ( $5 \mathrm{~m} \times 250 \mu \mathrm{m}$ i.d.), carrier gas He. a) column $\# 4, d_{f}=0.14 \mu \mathrm{m}$; b) column $\# 5, d_{f}=0.14 \mu \mathrm{m} ;$ c) column $\# 7, d_{f}=0.11$ $\mu \mathrm{m}$. For column number see Table 6.

\section{Table 6}

\section{Survey of the preparation procedure of some of the deactivated columns after coating and cross-linking (internal diameter of all the columns is $250 \mu \mathrm{m}$ ).}

\begin{tabular}{lll}
\hline $\begin{array}{l}\text { Reference number } \\
\text { from Table } 1\end{array}$ & $\begin{array}{l}\text { Deactivation } \\
\text { phenyl/vinyl/hydro- } \\
\text { silane ratio }\end{array}$ & Stationary phase \\
\hline 2 & $50: 7: 43$ & OV $-17(50 \% \mathrm{ph}-\mathrm{me})$ \\
4 & $6: 1: 93$ & OV $-73(5.5 \%$ diph $)$ \\
5 & $21: 3: 76$ & OV $-73(5.5 \%$ diph $)$ \\
7 & $35: 5: 60$ & OV $-61(33 \%$ diph $)$ \\
\hline
\end{tabular}

pared to $n$-tridecane have changed although the stationary phase is the same. In Figure $5 \mathrm{c}$ the effect of column polarity results in a relatively large shift of the $n$-alkanes. Peak symmetry particularly of critical components such as 1-octanol and nicotine is quite acceptable.

Due to the electron donating properties of the geminal phenyl groups and its chemical stability as expected the diphenyl substituted polysiloxanes showed an increased thermal stability. This is illustrated in Figures $\mathbf{6}$ and $\mathbf{7}$. In the first figure (6a) the separation of a plant extract with hydrocarbons up to $\mathrm{C}_{60}$ is shown. In the second figure (6b) a chromatogram of polymer additives with a molecular weight up to 1176 is demonstrated, similar separations on $\mathrm{OH}$-terminated diphenyl stationary phase have been published by Blum et al. [17]. In the latter case the column, which was coated with a commercially available OV-61 (33\% phenyl) stationary phase was temperature programmed to $420^{\circ} \mathrm{C}$. A separation of a mixture of triglycerides with this column is shown in Figure 7. 

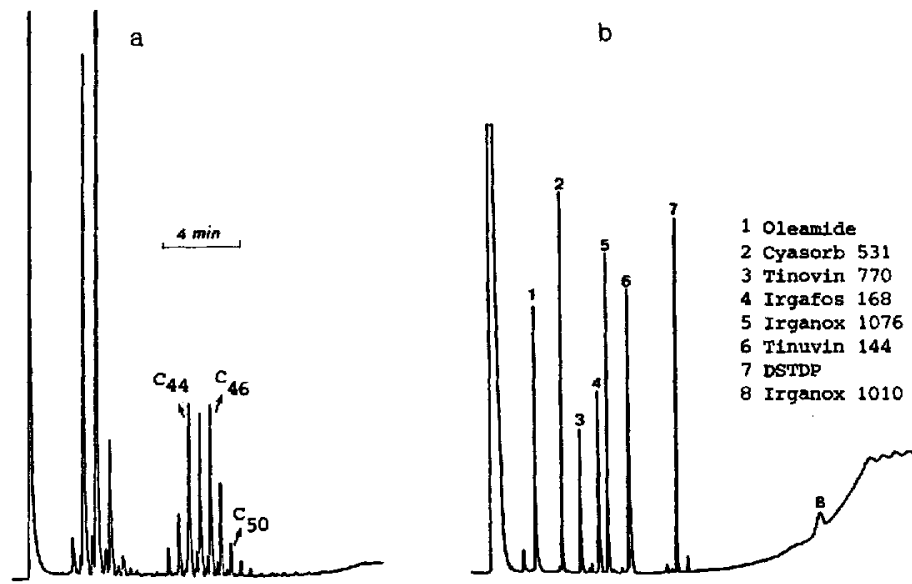

\section{Figure 6}

Representative chromatograms of a PDPVMHS deactivated OV-61 column ( $5 \mathrm{~m} \times 250 \mu \mathrm{m}$ i.d., $d_{\mathrm{f}}=0.07 \mu \mathrm{m}$, FID, f.s.d. $64 \times 10^{-12}$ ). a) A plant extraction product (column temperature from $150^{\circ} \mathrm{C}$ to $350^{\circ} \mathrm{C}$ at $20 \% \mathrm{~min}$ ); b) polymer additives in dichloromethane (column temperature from $150{ }^{\circ} \mathrm{C}$ to $350{ }^{\circ} \mathrm{C}$ at $20 \% \mathrm{~min}$ then to $420^{\circ} \mathrm{C}$ at $12 \% \mathrm{~min}$ ).

\section{Conclusions}

Polydiphenylvinylmethylhydrosiloxane (PDPVMHS) is an efficient deactivation reagent for fused silica capillary columns. The obtained deactivation layers are non-extractable and show a good wettability for phenylpolysiloxane stationary phases.

On the basis of off-line model experiments using solid state ${ }^{29} \mathrm{Si}$ NMR for studying the deactivated surface structures and properties of similarly deactivated Cab-O-Sil samples, the thickness of the deactivation layers can be estimated to be $1-2 \mathrm{~nm} .{ }^{29} \mathrm{Si}$ CP-MAS NMR provides valuable information on the structure and the properties of organo-silicious groups at a non-porous silica surface after silylation. The spectra obtained show that the deactivation layer is very stable up to $360^{\circ} \mathrm{C}$. Obviously the thermal stability of the deactivation layer is enhanced using the reagent with two phenyl groups connected to one silicon atom. Preliminary results with coated and cross-linked phenyl containing stationary phases are very promising.

\section{Acknowledgment}

Mrs. Denise Tiallema's assistance in the preparation of the manuscript is greatly appreciated.

\section{References}

[1] G.Schomburg, H. Husmann, and F. Weeke, Chromatographia 10 (1977) 580 .

(2) O. Wu, C. Cramers, and J. Rijks in P. Sandra (Ed.), "10th International Symposium on Capillary Chromatography", Riva del Garda, May 22-25, 1989, Hüthig, Heidelberg (1989), 188.

[3] C. L. Woolley, R. C. Kong, B. E. Richter, and M. L. Lee, HRC \& CC 7 (1984) 329 .

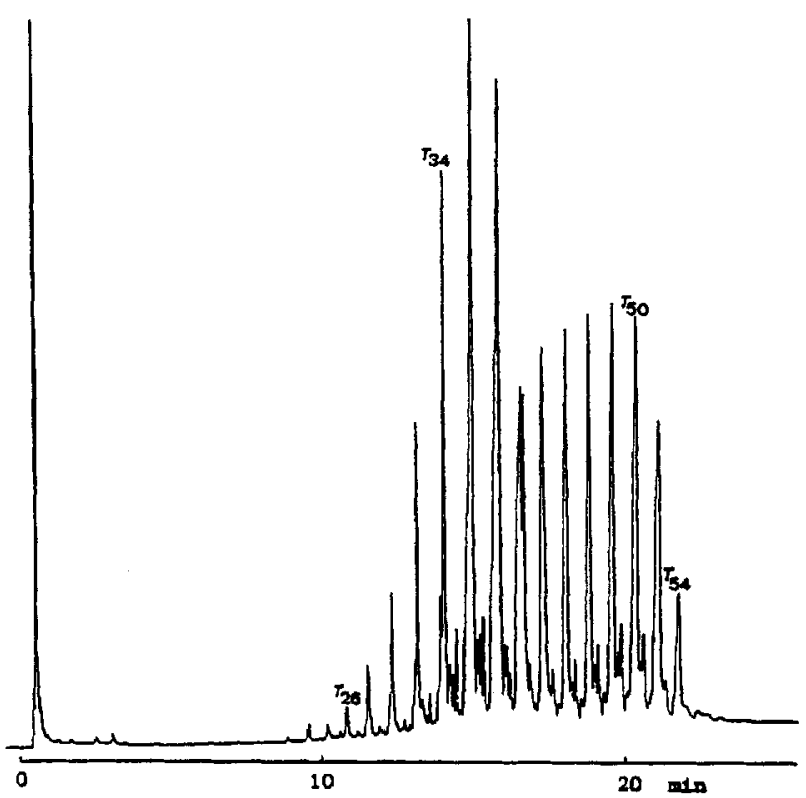

Figure 7

Representative chromatogram of a mixture of triglycerides on the same column as in Figure 6, column temperature from $40^{\circ} \mathrm{C}$ to $240^{\circ} \mathrm{C}$ at $20 \% \mathrm{~min}$, then to $380{ }^{\circ} \mathrm{C}$ at $10 \% \mathrm{~min}$.
[4] C. L. Woolley, B. E. Richter, M. L. Lee, and K. D. Bartle, HRC \& CC 9 (1986) 506.

[5] C. L. Woolley, B. E. Richter, and M. L. Lee, J. Chromatogr. 367 (1986) 9.

[6] C. L. Woolley, K. E. Markides, and M. L. Lee, J. Chromatogr. 367 (1986) 23.

[7] G. Rutten, A. van de Ven, J. de Haan, L. van de Ven, and J. Rijks, HRC \& CC 7 (1984) 607.

[8] K. Grob, G. Grob, and K. Grob, Jr., HRC \& CC 2 (1979) 31.

(9) K. Grob, G. Grob, and K. Grob, Jr., HRC \& CC 2 (1979) 677.

[10] K. Grob and G. Grob, 3 (1980) 197.

[11] T. Reiher, HRC \& CC 10 (1987) 158

[12] T. Welsch and H. Frank, HRC \& CC 8 (1985) 709

[13) W. Blum and G. Eglinton, HRC 12 (1989) 290.

[14] G. Rutten, J. de Haan, L. van de Ven, A. van de Ven, H. v. Cruchten, and J. Rijks, HRC \& CC $\mathbf{8}$ (1985) 664.

[15] M. Hetem, G. Rutten, B. Vermeer, J. Rijks, L. van de Ven, J. de Haan, and C. Cramers, J. Chromatogr. 477 (1989) 3.

[16] N. Grassie and I. G. McFarlane, Europ. Polymer Journal 14 (1978) 875.

[17] W. Blum and L. Damasceno, HRC \& CC 10 (1987) 472 